\title{
Application of the CATA methodology with children: Qualitative approach on ballot development and product characterization of innovative products
}

\author{
Célia Rocha $^{\mathrm{a}, \mathrm{b}, 1}$, José Carlos Ribeiro ${ }^{\mathrm{a}, \mathrm{b}, 1}$, Rui Costa Lima ${ }^{\mathrm{b}}$, Catarina Prista ${ }^{\mathrm{c}}$, \\ Anabela Raymundo $^{c}$, Maria Carlota Vaz Patto ${ }^{\mathrm{d}}$, Luís Miguel Cunha ${ }^{\mathrm{a} \text {,* }}$ \\ ${ }^{a}$ GreenUPorto-Sustainable Agrifood Production Research Centre, DGAOT, Faculty of Sciences, University of Porto, Campus de Vairão, Rua da Agrária, 747, $4485-646$ \\ Vila do Conde, Portugal \\ b Sense Test, Lda, Rua Zeferino Costa, 341, 4400-345 Vila Nova de Gaia, Portugal \\ ${ }^{c}$ LEAF, Linking Landscape, Environment, Agriculture and Food, Instituto Superior de Agronomia, Universidade de Lisboa, Tapada da Ajuda, $1349-017$ Lisboa, Portugal \\ ${ }^{\mathrm{d}}$ Instituto de Tecnologia Química e Biológica António Xavier, Universidade Nova de Lisboa, Av. da República, 2780-157 Oeiras, Portugal
}

\section{A R T I C L E I N F O}

\section{Keywords:}

Check-all-that-apply

Children

Fermented-grass pea

Food neophobia

Innovative food

Sensory evaluation

\begin{abstract}
A B S T R A C T
There is an increasing importance of the role of children and adolescents in the food market and to successfully develop food products intended for them, it is necessary to apply proper sensory evaluation methodologies. Although children can execute traditional methods for food liking and preference evaluation, traditional sensory descriptive methods may not be suitable for them and it is necessary to assess their ability to perform novel sensory profiling methods. Thus, this study aimed to assess children's acceptance of an innovative food product cookies incorporating fermented grass pea (Lathyrus sativus) flour - and their ability to describe a sensory profile using a Check-All-That-Apply (CATA) approach. Two different types of cookies (salty and sweet) were developed, differing in the level of substitution of wheat flour by fermented grass pea flour (between 0 and $40 \%$ ). The cookies were evaluated by two sensory panels of 60 children (8-12 years), who assessed the overall liking using a 7-point facial hedonic scale and the sensory profile of the samples using a CATA ballot with 21 sensory terms previously developed through focus groups with children. Children showed the ability to discriminate the different samples with the hedonic scale and according to their sensory profile. Results revealed that the focusgroup with children is an adequate way to generate CATA ballots and that the CATA approach is adequate to evaluate how children discriminate the sensory profile of food products. Furthermore, the food neophobia level of the children negatively impacted their acceptance of the food products.
\end{abstract}

\section{Introduction}

Children and adolescents are groups of consumers presenting an increasing importance in the food market, having a great influence in the purchase of food products, either through direct influence on their parents' purchase decisions or even by buying the products themselves (Laureati \& Pagliarini, 2018; Laureati, Pagliarini, Toschi, \& Monteleone, 2015; Popper \& Kroll, 2011). It is therefore essential that food manufacturers optimize the products intended for children and adolescents, by matching the sensory expectations of these particular consumers.

Involving children in product development can also play a significant role in reducing obesity and malnutrition through a better understanding of the main processes influencing the acquisition of eating patterns (WHO, 2012). Reflecting this, most studies published in the 21st century about consumer perception and sensory analysis with young consumers have dealt with healthy eating habits (Laureati et al., 2015). Childhood obesity is one of the most serious public-health crisis of the 21 st century, and children's eating habits are major factors in the development of these diseases (Lobstein, Baur, \& Uauy, 2004). The unhealthy food habits of children and adolescents are related to several risk factors such as marketing of foods rich in fat, sugar and salt (Kelly et al., 2010) and individual food preferences (Birch, 1999).

\footnotetext{
Abbreviations: CATA, check-all-that-apply; CFNS, child food neophobia scale.

* Corresponding author at: GreenUPorto/DGAOT, Faculty of Sciences, University of Porto, Campus Agrário de Vairão, Rua da Agrária, 747, 4485-646, Vila do Conde, Portugal.

E-mail address: lmcunha@fc.up.pt (L.M. Cunha).

${ }^{1}$ Equal contribution.
} 
Sensory analysis of products intended for children should be performed with them and not with adults, as adults and children have different sensory perceptions and preferences. These two groups have reported differences in sweet and sour taste as well as texture discrimination and preference (Laureati et al., 2015; Sune, Lacroix, \& Huon de Kermadec, 2002). These differences may be related to different perceptions of texture and slower or reduced flavor release which impacts products' liking (Rose, Laing, Oram, \& Hutchinson, 2004). However, the complexity of the applied sensory evaluation method or the stimuli can also play a significant role (Popper \& Kroll, 2011). These differences are less noticeable in the evaluation of appearance since children can generate and evaluate attributes related to appearance at an adequate level (Rose et al., 2004; Sune et al., 2002). Regarding odor abilities, although no-marked differences in olfactory thresholds have been reported in literature, children are less capable of describing the odors (Lehrner, Glück, \& Laska, 1999).

Children make their food choices mostly based on liking, considering sensory properties, mostly sweet taste, appearance and texture, as crucial points on this decision process (Laureati et al., 2015). This is evident on children's rejection of healthy foods such as fruits, vegetable and fiber-enriched products because although they are able to differentiate between healthy and unhealthy food (Varela \& Salvador, 2014), they still reject these kinds of food due to bitter or unfamiliar tastes and textures which are not easily controllable in the mouth (Zeinstra, Koelen, Kok, \& de Graaf, 2010).

Individual characteristics of the children can also influence their food preferences. One of these characteristics can be food neophobia, which is a psychological construct that describes a person's tendency to reject or avoid eating unfamiliar foods or foods from other cultures (Pliner, 1994). High scores in children food neophobia have been associated with a less diversified and healthy diet, with low preferences for healthy foods (and in particular fruits, vegetables and legumes) (Gomes, Barros, Pereira, Roberto, \& Mendonça, 2018; Howard, Mallan, Byrne, Magarey, \& Daniels, 2012; Russell \& Worsley, 2008). Furthermore, high levels of food neophobia have also been associated with a preference for softer textures (Laureati et al., 2020) and decreased acceptance of fiber-enriched products (Proserpio et al., 2020; Proserpio, Lavelli, Gallotti, Laureati, \& Pagliarini, 2019). Children's neophobia may also affect the parents' attitudes regarding children food habits, since they tend to offer less uncommon or healthy foods when their children are more neophobic (Coulthard \& Blissett, 2009; Koivisto \& Sjödén, 1996).

Sensory analysis with children can be a demanding task, since the choice of a suitable method is related to the children' cognitive abilities, which are different from adults. Children as young as 4-5 years old, have shown to be able to use hedonic scales in order to assess differences in liking regarding different products (Caporale, Policastro, Tuorila, \& Monteleone, 2009; Olsen, van Belle, Meyermann, \& Keller, 2011). Although several scales have been applied, the most used are five and seven-point facial hedonic scales (Laureati et al., 2015).

Regarding sensory profiling, traditional descriptive methods may not be suitable for children due to their complexity (Laureati et al., 2015). These methods require training for the correct and objective use of scales. Their suitability may also be jeopardized due to children behavior, which are mostly irrational and spontaneous, and changing through time, since it is in childhood that children acquire most of the rules related not only with the food but also with life (Birch, Savage, \& Ventura, 2007).

In last years, several new techniques have been developed which are intended for naïve consumers and could also be used with children, such as Projective Mapping (Mitterer-Daltoé et al., 2017) or structured sorting (Varela \& Salvador, 2014). Check-All-That-Apply (CATA) methodology is also a recent technique, which allows the sensory profiling of food products through the selection of attributes presented in a ballot, and has been extensively used with adults (Ares, Barreiro, Deliza, Giménez, \& Gámbaro, 2010; Dooley, Lee, \& Meullenet, 2010; Ribeiro et al., 2019). Due to the simplicity of the process and low-cognitive effort that is required, this method has already been applied with children not only to obtain sensory (Laureati \& Pagliarini, 2018) but also emotional profiles (De Pelsmaeker, Schouteten, \& Gellynck, 2013).

Regarding sensory profiles, CATA questions have been performed with children as young as 6 years old (Lima, Ares, \& Deliza, 2018; 2019) and with several different products: apple purées (Laureati et al., 2017), grape nectar (Lima et al., 2018; 2019), biscuits (Schouteten, De Steur, Lagast, De Pelsmaeker, \& Gellynck, 2017; Verwaeren, Gellynck, Lagast, \& Schouteten, 2019) and fruit juices (Cardinal, Zamora, Chambers, Carbonell Barrachina, \& Hough, 2015). Regardless age and type of product, children have been able to perform this methodology and to differentiate samples according to their sensory profile and even give additional insights (e.g. food products characterization and sensory drivers of liking) not available with the use of other traditional methods (Lima et al., 2018). One of the main challenges of performing CATA questions with children is the development of the ballot, since the sensory attributes used should be suitable for children. So far, most studies carrying out this methodology with children have used free listing questionnaires (Laureati et al., 2017) or focus groups (Schouteten et al., 2017; Verwaeren et al., 2019).

In the case of emotional profiling, although lists of words representing emotions have been utilized (De Pelsmaeker et al., 2013; Gallo, Swaney-Stueve, \& Chambers, 2017) most studies have used ballots with Emojis (Gallo et al., 2017; Schouteten et al., 2017; Schouteten, Verwaeren, Gellynck, \& Almli, 2019; Schouteten, Verwaeren, Lagast, Gellynck, \& De Steur, 2018).

The main goal of this work was to assess children's ability to evaluate innovative food product (cookies incorporating grass-pea based tempeh flour), validating their ability to participate in the generation of a CheckAll-That-Apply ballot and to perform this methodology. Furthermore, the impact of children's characteristics (age, sex and food neophobia) on the overall liking was evaluated and the sensory drivers of liking were identified.

\section{Material and methods}

\subsection{Samples formulation and elaboration}

A traditional grass pea (Lathyrus sativus L.) variety produced by a local farmer (Simões \& Ramos Lda.) from Alvaiázere region, was used in this study. Due to its relatively low input requirements compared to major crops and its interesting nutritional profile, grass pea is considered a model grain legume crop for sustainable agriculture (Vaz Patto, 2006). In Portugal, it is part of the traditional heritage of dryland communities, representing an important source of revenue for some local economies (Vaz Patto \& Araújo, 2016) Nonetheless, consumption of grass pea is uncommon and it is an ingredient unfamiliar to the majority of Portuguese consumers. Furthermore, its processing from fermentation into flour and further incorporation into bakery products has never been performed.

Grass pea-based tempeh was developed through a fermentation process adapted from Tibbott (2004). Briefly, grass pea seeds were soaked in demineralized water at room temperature overnight. After draining, the soaked seeds were pressured cooked for $5 \mathrm{~min}$, cooled to $30{ }^{\circ} \mathrm{C}$, dehulled and dried between absorbent paper sheets. Then, $400 \mathrm{~g}$ of cooked grass pea seeds were mixed with $10 \mathrm{~mL}$ of vinegar, inoculated with Rhizopus microsporus var. oligosporus $\left(10^{5}\right.$ spores/g of grass pea seeds) isolated from a commercial tempeh starter (TopCultures, Zoersel, Belgium) and spread on polyethylene bags perforated with a sewing needle in a grid pattern with approximately $1-1.5 \mathrm{~cm}$ intervals. The bags were sealed and pressured to distribute the grass pea seeds in a uniform layer $2 \mathrm{~cm}$ thick. Tempeh containers were placed in a ventilated incubator over a rack to aid air circulation and incubated for $36 \mathrm{~h}$ at $30^{\circ} \mathrm{C}$, until the grass pea seeds were bound into a firm compact cake by a dense, uniform white mycelium permeating the entire cake. Tempeh 
cake was sliced and dried in a ventilated oven at $95^{\circ} \mathrm{C}$ for $3 \mathrm{~h}$. To obtain a flour-like powder from grass pea based tempeh, the dehydrated tempeh slices were milled and sieved to a size particle less than $2 \mathrm{~mm}$ in a Pulverisette 14 Premium (Fritsch), and kept at room temperature in a closed container, with silica gel and protected from light, until use. The grass pea-based tempeh flour was used for incorporation in two different basic recipes of cookies, salty and sweet. For each type of cookies, five different formulations were developed, differing in the level of substitution of wheat flour by grass pea-based tempeh flour. Sweet cookies formulation was adapted from Fradinho, Nunes, and Raymundo (2015) with the addition of grass pea tempeh flour at 10\%, 20\%,30\% and $40 \%$ $(\mathrm{w} / \mathrm{w})$ incorporation by replacing a corresponding amount of flour. Salty cookies formulation was adapted from Batista et al. (2019) with the addition of grass pea tempeh flour at 5\%,10\%, 20\% and $30 \%(\mathrm{w} / \mathrm{w})$ incorporation by replacing a corresponding amount of flour. For both typologies, a control sample with no grass pea-based tempeh flour was used.

\subsection{Experimental design}

In order to achieve the proposed research goals, two different phases were carried out, with a week difference between them. In the first phase, children were invited to participate in a focus groups aiming to generate a list of attributes for the development of a CATA ballot. In the second phase, two children' panels rated their overall liking and performed the sensory profiling of the samples.

\subsection{Phase 1: CATA ballot development}

\subsubsection{Focus groups}

In order to develop the CATA ballot for the sensory profiling of the cookie samples, focus groups were performed. In total, four focus groups, with 5 children each, were performed. The groups were selected based on sex (boys and girls) and age (8 to 10 years old and 11 to 12 years old). Recruitment was based on the previous identification of adult consumers from Sense Test's (a sensory evaluation and consumer tests company) consumer database with children at their households. Children willing to participate were identified and each participation was fully authorized. Parents gave their informed consent for their children participation, in accordance with the ASTM E2299-13 Standard Guide for Sensory Evaluation of Products by Children and Minors.

Focus groups discussions took place at Sense Test's focus group room, during August 2018, and had a duration of approximately $30 \mathrm{~min}$. All the sessions were conducted by the same experienced researcher, one of the first authors, to ensure consistency in interviewing style (Partridge, Edwards, \& Thorpe, 2010). The moderator was assisted by other co-authors to deal with video recording and some important annotations about participants' behavior.

The focus group guide was based on the work of Rose et al. (2004). After an initial icebreaker introduction, the task was split into three main phases: (i) exercise contextualization - children were asked to describe some geometric solids, namely to describe "how do they look?" and "what did they think that is important in the figures?"; (ii) exercise with food - children were asked to indicate how do apples look, smell and taste, and then they were invited to find the best words (from the ones elicited) to describe the apples; (iii) product description - children were asked to describe the cookies samples (appearance, smell, texture and taste), and then they were invited to indicate which characteristics better fit the cookies.

The focus group sessions were video recorded for accuracy of transcription and analysis (following participants' informed consent). All the recordings were anonymously transcribed verbatim.

\subsubsection{Data analysis}

The focus group transcriptions were analyzed, and themes were developed by the researchers, based upon the core themes of the focus group guide, considering similarities and differences of participants' responses (Bardin, 1977). In this specific work, the core themes were sensory dimensions and the characteristics that children perceived in each dimension. To illustrate the analysis, direct quotes by the participants were transcribed, serving as a description of the topic explored. For each elicited term, an absolute frequency was calculated. Due to the similarity of terms and in order to have a more comprehensive ballot, a common list for both cookies was created for the CATA ballot.

Data analysis was performed using the XL-STAT 2019® (Addinsoft 2019) and Statistical Package for Social Sciences (SPSS) - version $25 \circledR$ software.

\subsection{Phase II: Evaluation of the samples with different grass pea-based tempeh flour incorporation}

\subsubsection{Sensory evaluation}

Considering the previously established ballot, two panels of 60 children (between 8 and 12 years old) were invited to evaluate the different samples described in Section 2.1. Recruitment was based on the previous identification of adult consumers from Sense Test's consumer database with children at their households. Children willing to participate were identified, with each participation being authorized. All parents gave their written informed consent for their children participation, in accordance with the ASTM E2299-13 Standard Guide for Sensory Evaluation of Products by Children and Minors.

The panel for sweet cookies evaluation had an average age of 10.3 $( \pm 1.5)$ years and had a proportion of $52 \%$ girls. The panel for salty cookies had an average age of $10.2( \pm 1.4)$ years and had a proportion of $53 \%$ girls.

For each sample, children were asked to score their overall liking, using a 7-point facial hedonic scale (ASTM, 2003), ranging from 1 "very bad" to 7 - "very good", before evaluating the CATA ballot, as a way to avoid potential hedonic score bias (King, Meiselman, \& Carr, 2013). The CATA terms were presented in a random order between participants and between samples (Ares et al., 2013) and divided by sensory modalities to reduce the cognitive effort of the participants (Ares \& Jaeger, 2013).

The tests were performed at Sense Test's sensory evaluation lab, in a special room with individual tasting booths equipped in accordance with ISO 8589:2007 - Sensory analysis - General guidance for the design of test rooms. Prior to the evaluation of the samples, the general procedure and the attributes in the CATA ballot were explained to each child individually by an experienced researcher and afterwards children practiced the evaluation procedure with a dummy sample (unsalted cracker). For each sample evaluation, children were provided with two cookies from the same formulation on plastic plates identified by a three-digit random number, under normal white lighting. Two cookies were provided to ensure that children had a representative amount of the sample to perform both liking and Check-All-That-Apply methods.

All samples were presented following a monadic balanced order of presentation, according to the Latin square design, to counterbalance possible carry-over effects (Macfie, Bratchell, Greenhoff, \& Vallis, 1989). Participants were provided with a porcelain spittoon, a glass of bottled natural still water and unsalted crackers and were asked to chew a piece of cracker and to rinse the mouth with water between each sample, to rinse the palate. Tasting was performed under the surveillance of the researchers and all children willingly followed the test instructions, without any major difficulty.

\subsubsection{Children food neophobia}

In order to assess the food neophobia level of the participants, the children's parents answered the 10-item Children Food Neophobia Scale - CFNS (Pliner, 1994). This questionnaire consists of five neophobic and five neophilic statements regarding food consumption. Parents answer the level of agreement in a 7-point scale, ranging from "strongly disagree" to "strongly agree", when considering their own children's 
eating behavior. After reversing the scores given to the neophilic statements, the CFNS scores were calculated as the sum of the ratings in each statement, ranging from 10 to 70 with higher scores corresponding to higher levels of Food Neophobia.

\subsubsection{Data analysis}

Regarding the CFNS scale, the panel was divided into three groups (Table 1) according to the frequency distribution of the CFNS scores: class 1 (children in the lowest quartile, CFNS score lower than 21.5), class 2 (children in the second and third quartile, CFNS score between 21.5 and 40) and class 3 (children in the last quartile, CFNS score greater than 40). Children were also divided according to age - group 1 (8-10 years old) and group 2 (11 and 12 years old) - and sex. The results of overall liking were evaluated with descriptive statistics (mean and standard error of the mean) and with a 4-way ANOVA, where age, sex, neophobia class and level of replacement were used as main factors, followed by the LSD (Least Significant Difference) multiple comparison test. The second order interactions of this factors were also evaluated at a $95 \%$ confidence level.

To analyze CATA questions, frequency of use of each term was determined by counting the number of consumers who have used each attribute to describe the samples and a Cochran $Q$ test at a $95 \%$ confidence level was initially used to identify significant differences perceived by consumers between samples for each of the terms (Parente, Manzoni, \& Ares, 2011).

In order to obtain a two-dimensional representation of the samples, a correspondence analysis (CA) was applied from the previously determined contingency table. This analysis provides a sensory map of the samples, allowing the determination of similarities and differences between samples as well as the features that characterize its attributes (Ares, Varela, Rado, \& Giménez, 2011). A multidimensional alignment (MDA) was also applied to assess the degree of multidimensional association between products and attributes presented on the perceptual map (Meyners \& Castura, 2014; Meyners, Castura, \& Carr, 2013). Both the CA and MDA analyses were performed with only the attributes that differentiated the samples according to the Cochran Q test. Additionally, to have a deeper understanding of the impact of each sensory attribute (evaluated on the CATA ballot) on liking, a penalty analysis was applied. Indeed, for each type of cookie, the impact of each significant sensory attribute (retained with the application of Cochran's test) on liking scores was measured, evaluating if the presence of the attribute represents a significant penalty or an added-value for sample liking (Ares et al., 2014).

Table 1

Socio-demographic characteristics, average FNS score and n (number of children) in each CFNS class.

\begin{tabular}{|c|c|c|c|}
\hline CFNS class & Characteristics & $\begin{array}{l}\text { Sweet } \\
\text { cookies }\end{array}$ & $\begin{array}{l}\text { Salty } \\
\text { cookies }\end{array}$ \\
\hline \multirow[t]{4}{*}{ Class 1 - Low neophobia level } & $\mathrm{n}$ & 14 & 15 \\
\hline & $\begin{array}{l}\text { Age - years }( \pm S \text {. } \\
\text { D) }\end{array}$ & $10.0( \pm 1.6)$ & $9.9( \pm 1.5)$ \\
\hline & FNS $( \pm$ S.D) & $17.3( \pm 2.9)$ & $\begin{array}{l}17.7( \pm \\
2.9)\end{array}$ \\
\hline & $\operatorname{Sex}(M / F \%)$ & $36 / 64$ & $40 / 60$ \\
\hline \multirow{4}{*}{$\begin{array}{c}\text { Class } 2 \text { - Intermediate } \\
\text { neophobia level }\end{array}$} & $\mathrm{n}$ & 30 & 29 \\
\hline & $\begin{array}{l}\text { Age - years }( \pm S \text {. } \\
\text { D) }\end{array}$ & $10.4( \pm 1.3)$ & $\begin{array}{l}10.2( \pm \\
1.3)\end{array}$ \\
\hline & FNS $( \pm$ S.D $)$ & $33.6( \pm 4.7)$ & $\begin{array}{l}34.1( \pm \\
4.6)\end{array}$ \\
\hline & Sex (M/F \%) & $63 / 37$ & $55 / 45$ \\
\hline \multirow[t]{4}{*}{ Class 3 - High neophobia level } & $\mathrm{n}$ & 13 & 15 \\
\hline & $\begin{array}{l}\text { Age - years }( \pm S \text {. } \\
\text { D) }\end{array}$ & $10.4( \pm 1.6)$ & $\begin{array}{l}10.3( \pm \\
1.3)\end{array}$ \\
\hline & FNS $( \pm$ S.D $)$ & $47.9( \pm 7.4)$ & $\begin{array}{l}47.1( \pm \\
6.7)\end{array}$ \\
\hline & $\operatorname{Sex}(M / F \%)$ & $23 / 77$ & $33 / 67$ \\
\hline
\end{tabular}

\section{Results}

\subsection{CATA ballot development}

Children elicited a total of 60 sensory attributes for the sweet cookies and 57 for the salty cookies and for both types of cookies most of the attributes were related to appearance ( 23 for sweet cookies and 21 for salty cookies). On the other hand, the sensory dimension that had fewer attributes was texture, with only five different attributes being elicited for sweet cookies and eight for salty cookies. Although children elicited a great number of attributes related to appearance, in the final list only 3 attributes were chosen for appearance. This is explained by the great number of redundant elicited attributes (e.g. tires, wheels, round, different types of wheels) and/or low frequency of mention. To have a broader applicability, the same ballot was utilized for both typologies of cookies, salty and sweet, with two specific taste attributes for each: salty -'water \& salt cookie' and 'salty taste'-; sweet -'sweet taste' and 'Maria cookie'-.

The final CATA ballot (Table 2) was comprised of 21 attributes divided by sensory dimensions - appearance (3), odor (5), texture (4) and taste (9).

3.2 Overall liking - effects of sample and children's traits and characteristics

For the sweet cookies, it was possible to see that the sample with the highest overall liking had a $10 \%$ wheat flour substitution by grass-pea based tempeh flour (Table 3), with no significant differences with the $20 \%$ of flour substitution sample or control sample. However, with $30 \%$ and $40 \%$ of flour substitution, the samples had the lowest scores in overall liking, with the sample with $40 \%$ of flour substitution having significant differences in overall liking scores for all the other samples.

For the salty cookies, the control sample had the highest score in overall liking, with significant differences for the samples with 5\%, 20\% and $30 \%$ of flour substitution (Table 2). The samples with $10 \%$ flour substitution had the second highest overall liking score, although with no significant differences for any other sample.

Regarding the individual characteristics of the children, only the CFNS class had a significant impact on the overall liking of both types of cookies (Table 3 ), while age group ( $p=0.266$ for sweet cookies; $p=$ 0.255 for salty cookies) and sex ( $p=0.248$ for sweet cookies; $p=0.2828$ for salty cookies) had no significant impact. Additionally, the interactions between samples and children's characteristics -age group $(p$ $=0.672$ for sweet cookies; $p=0.598$ for salty cookies $)$, sex $(p=0.681$ for sweet cookies; $p=0.573$ for salty cookies) and CFNS class ( $p=0.586$ for sweet cookies; $p=0.818$ for salty cookies), had no significant impact on the overall liking for both types of cookies. Furthermore, the interaction 'CFNS class $\times$ sex' had a significant impact on the overall liking of the sweet cookies $(F(2,255)=6.435 ; p=0.002)$, with neophobia level having a more significant impact for boys than for girls.

Similar behaviors were observed when analyzing the impact of the CFNS class on overall liking for each type of cookie, given that the most neophobic group (class 3 ) gave the lowest overall liking scores with a significant difference from the other groups (classes 1 and 2) (Table 3).

\subsection{Sensory profile}

Results yielded different levels of discrimination for each type of cookies, with the panel for sweet cookies identifying $71,4 \%$ of the attributes $(15 / 21)$ as discriminant and the panel for salty cookies identifying $42.9 \%$ of the attributes (9/21) as discriminant (Table 2). The main differences between the two types of cookies were observed for the attributes related to taste, since in the evaluation of salty cookies only 2 out of 9 attributes differentiated the samples ('salty' and 'toasted'), while in the evaluation of sweet cookies 8 out of 9 had that effect ('Maria cookie, 'water \& salt cookie', 'sweet', 'cereals', 'unpleasant', 'unpleasant aftertaste', 'wholegrain cookie', 'toasted'). For other sensory dimensions, differences were found for the attributes 'crunchy' (only 
Table 2

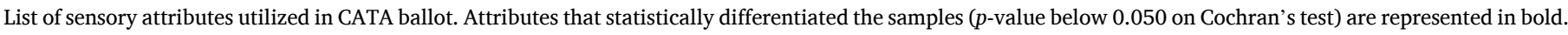

\begin{tabular}{|c|c|c|c|c|c|c|c|c|c|c|c|}
\hline \multicolumn{3}{|l|}{ Appearance } & \multicolumn{3}{|l|}{ Odor } & \multicolumn{3}{|l|}{ Texture } & \multicolumn{3}{|l|}{ Taste } \\
\hline & Sweet & Salty & & Sweet & Salty & & Sweet & Salty & & Sweet & Salty \\
\hline $\begin{array}{l}\text { Wholegrain } \\
\text { cookie }\end{array}$ & $<0.001$ & $<0.001$ & Toast & $<0.001$ & $<0.001$ & $\begin{array}{l}\text { Crumbles } \\
\text { easily }\end{array}$ & 0.385 & 0.361 & Water \& salt cookie & 0.021 & 0.052 \\
\hline Dark color & $<0.001$ & $<0.001$ & Raw dough & 0.646 & 0.007 & Dry & 0.615 & 0.064 & Wholegrain cookie & 0.030 & 0.064 \\
\hline \multirow[t]{7}{*}{ Tempting } & $<0.001$ & $<0.001$ & Water \& salt cookie & 0.022 & 0.045 & Crunchy & 0.023 & 0.511 & $\begin{array}{l}\text { Unpleasant taste at the } \\
\text { end }\end{array}$ & 0.017 & 0.093 \\
\hline & & & Odorless & 0.001 & 0.178 & Easy to chew & 0.945 & 0.182 & Cereals & 0.027 & 0.219 \\
\hline & & & Wholegrain cookie & 0.065 & 0.045 & & & & Toasted & $<0.001$ & 0.009 \\
\hline & & & & & & & & & Maria cookie & $<0.001$ & 0.736 \\
\hline & & & & & & & & & Sweet & $<0.001$ & 0.104 \\
\hline & & & & & & & & & Salty & 0.539 & 0.007 \\
\hline & & & & & & & & & Unpleasant & 0.010 & 0.121 \\
\hline
\end{tabular}

Table 3

Mean overall liking, based on 7-point facial hedonic scale, ( \pm SD) according to type of cookie for different levels of incorporation of fermented grass pea flour and for different CFNS classes. F-values from the 4-way ANOVA, with age, sex, neophobia class and samples as factors on overall liking.

\begin{tabular}{|c|c|c|c|c|c|}
\hline \multicolumn{3}{|c|}{ Sweet cookies } & \multicolumn{3}{|c|}{ Salty cookies } \\
\hline & $\begin{array}{l}\text { Mean } \\
( \pm \mathrm{SD})\end{array}$ & $\begin{array}{l}F\left(\mathrm{df}_{(\text {level, error })}\right) \\
p\end{array}$ & & $\begin{array}{l}\text { Mean } \\
( \pm \text { SD })\end{array}$ & $\begin{array}{l}F\left(\mathrm{df}_{(\text {level, }}\right. \\
\text { error }) ; p\end{array}$ \\
\hline Control & $\begin{array}{l}5.9( \pm \\
1.2)^{\mathrm{a}, \mathrm{b}}\end{array}$ & $\begin{array}{l}F(4,255)= \\
8.199 ; p<\end{array}$ & Control & $\begin{array}{l}5.9( \pm \\
0.9)^{\mathrm{a}}\end{array}$ & $\begin{array}{l}F(4,265)= \\
2.415 ; p=\end{array}$ \\
\hline $10 \%$ & $\begin{array}{l}6.1( \pm \\
1.2)^{\mathrm{a}}\end{array}$ & 0.001 & $5 \%$ & $\begin{array}{l}5.2 \pm \\
(1.5)^{b}\end{array}$ & 0.049 \\
\hline $20 \%$ & $\begin{array}{l}5.9( \pm \\
1.2)^{\mathrm{a}, \mathrm{b}}\end{array}$ & & $10 \%$ & $\begin{array}{l}5.6 \pm \\
(1.4)^{\mathrm{a}, \mathrm{b}}\end{array}$ & \\
\hline $30 \%$ & $\begin{array}{l}5.7( \pm \\
1.1)^{\mathrm{b}}\end{array}$ & & $20 \%$ & $\begin{array}{l}5.2 \pm \\
(1.5)^{b}\end{array}$ & \\
\hline $40 \%$ & $\begin{array}{l}4.9( \pm \\
1.4)^{\mathrm{c}}\end{array}$ & & $30 \%$ & $\begin{array}{l}5.3 \pm \\
(1.5)^{b}\end{array}$ & \\
\hline $\begin{array}{l}\text { CFNS } \\
\text { class }\end{array}$ & $\begin{array}{l}\text { Mean } \\
( \pm \text { SD })\end{array}$ & $\begin{array}{l}F\left(\mathrm{df}_{\text {(CFNS, }}\right. \\
\text { error }) ; p\end{array}$ & $\begin{array}{l}\text { CFNS } \\
\text { class }\end{array}$ & $\begin{array}{l}\text { Mean } \\
( \pm \mathrm{SD})\end{array}$ & $\begin{array}{l}F\left(\mathrm{df}_{\text {(CFNS, }}\right. \\
\text { error }) ; p\end{array}$ \\
\hline 1 & $\begin{array}{l}6.0( \pm \\
1.2)^{\mathrm{a}}\end{array}$ & $\begin{array}{l}F(2,255)= \\
13.090 ; p<\end{array}$ & 1 & $\begin{array}{l}5.5( \pm \\
1.3)^{\mathrm{a}}\end{array}$ & $\begin{array}{l}F(2,265)= \\
3.703 ; p=\end{array}$ \\
\hline 2 & $\begin{array}{l}5.7( \pm \\
1.2)^{\mathrm{a}}\end{array}$ & 0.001 & 2 & $\begin{array}{l}5.6( \pm \\
1.3)^{\mathrm{a}}\end{array}$ & 0.026 \\
\hline 3 & $\begin{array}{l}5.2( \pm \\
1.3)^{\mathrm{b}}\end{array}$ & & 3 & $\begin{array}{l}5.0( \pm \\
1.7)^{\mathrm{b}}\end{array}$ & \\
\hline
\end{tabular}

a,b,c- homogeneous groups in accordance with the LSD test $(\mathrm{p}<0.050)$.

discriminant for sweet cookies), odor of 'raw dough' and 'wholegrain cookie' (only discriminant for salty cookies) and 'odorless' (only discriminant for sweet cookies). For the attributes related to appearance, all the attributes presented in the ballot differentiated the samples for both types of cookies.

The Correspondence Analysis of the CATA frequencies (Fig. 1) and the MDA (Fig. 2 and Fig. 2) allowed to better understand how the addition of grass pea-based tempeh flour affected the sensory profiling of sweet and salty cookies by children. For sweet cookies (Fig. 1a and Fig. 2), it is possible to see that the samples with the highest incorporation (30 and 40\% flour substitution) were associated with 'dark color', 'wholegrain' appearance, 'toast' odor, 'toasted' taste, 'unpleasant' taste, 'unpleasant aftertaste', and taste of 'wholegrain cookie'. On the other hand, the control sample and cookies with 10 and $20 \%$ flour substitution had different sensory profiles. Both the control and cookies with $10 \%$ flour substitution were associated with a 'sweet' taste, 'crunchy' texture and tempting appearance. The addition of grass pea-based tempeh flour made the samples with $10 \%$ and $20 \%$ flour substitution to be associated with a 'cereals' taste, while the association with 'odorless', odor of 'water \& salt' cookie, taste of 'water \& salt' cookie and 'Maria cookie' taste was weaker than for the control sample.

Concerning the attributes that were identified through penalty analysis as having a significant impact on the overall liking of sweet

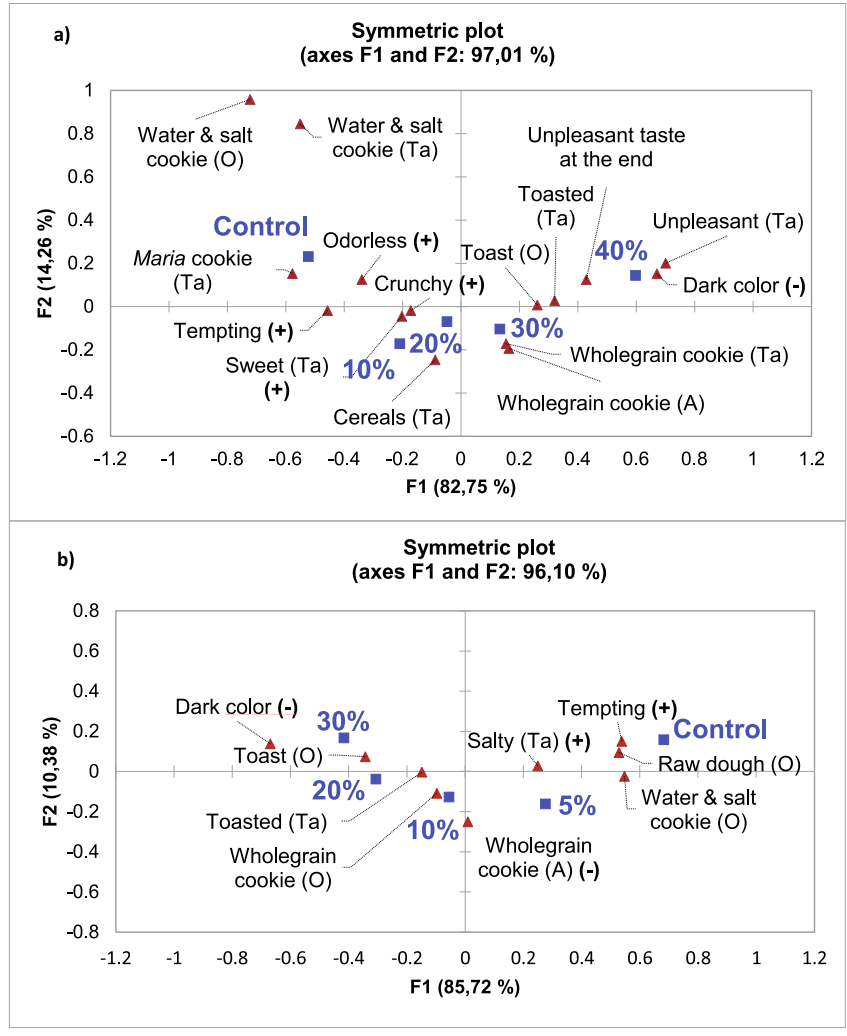

Fig. 1. Correspondence Analysis of CATA frequencies containing only the attributes related to appearance (A), texture, odor (O) and taste (Ta) that significantly differentiated the sweet cookies (graph a) and the salty cookies (graph b) samples (according to the Cochran Q test at 95\% significance level). Attributes represented with symbols $(+)$ or $(-)$, were identified as having a significant impact on the overall liking of the sweet cookies (a) and salty cookies (b) through Penalty Analysis.

cookies, it was found that 'tempting' appearance, 'crunchy' texture, 'sweet' taste and 'odorless' had a positive impact and were mostly associated with the control sample and cookies with $10 \%$ flour substitution. On the other hand, 'dark color' had a negative impact on overall liking and was associated with cookies with $30 \%$ or $40 \%$ flour substitution.

For the salty cookies (Fig. 1b and Fig. 3), a similar performance in the sensory profile was also observed. The samples with the highest incorporation (20\% and $30 \%$ substitution), were associated with a 'dark color', 'toast' odor, 'toasted' taste and odor of 'wholegrain cookie'. The control sample (which was the sample with the highest overall liking score), was associated with a 'salty' taste, 'tempting' appearance, odor of 'raw dough' and odor of 'water \& salt cookie'. The incorporation of 

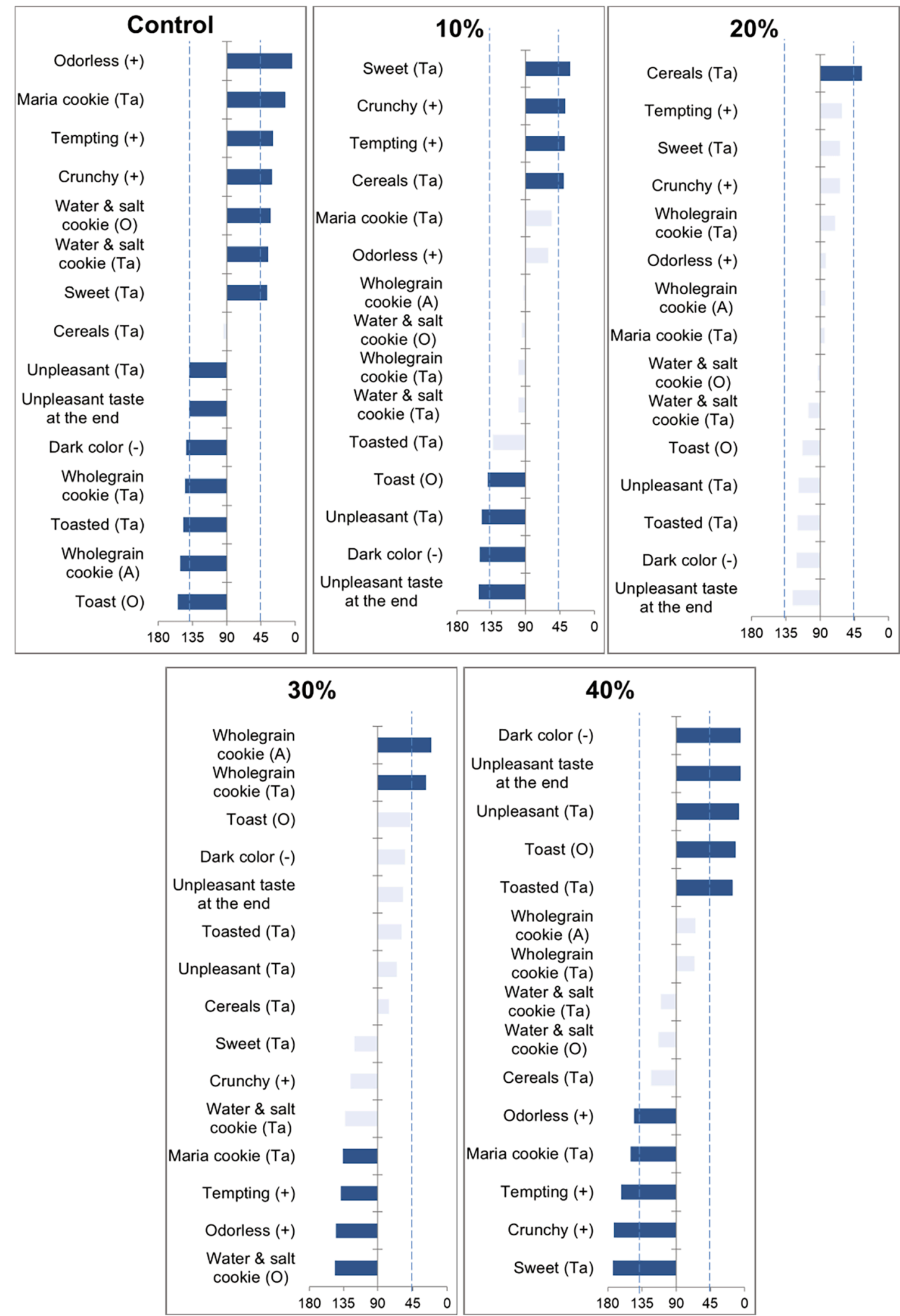

Fig. 2. Results of MDA analysis, with cosines of the angles between the samples and all the attributes that significantly differentiated the sweet cookies samples (according to the Cochran $Q$ test at $95 \%$ significance level). Vertical dashed lines indicate the cut-off values of $\cos \left(45^{\circ}\right)$ and $\cos \left(135^{\circ}\right)-$ which represent positive and negative correlations between samples and attributes, respectively. Attributes represented with symbols ( + ) or (-), were identified as having a significant impact on the overall liking of the sweet cookies through Penalty Analysis. 

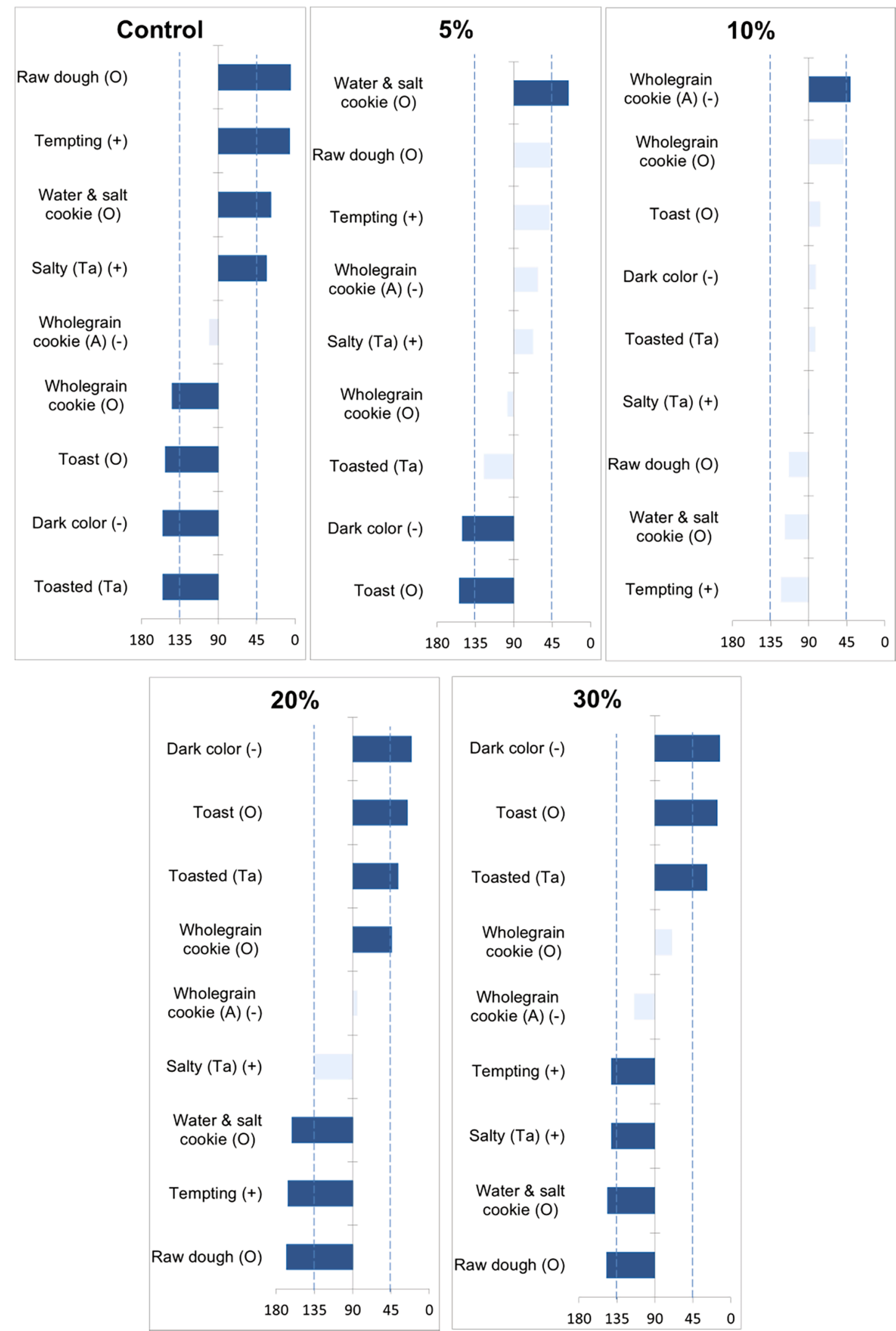

Fig. 3. Results of MDA analysis, with cosines of the angles between the samples and all the attributes that significantly differentiated the salty cookies samples (according to the Cochran $Q$ test at $95 \%$ significance level). Vertical dashed lines indicate the cut-off values of $\cos \left(45^{\circ}\right)$ and $\cos \left(135^{\circ}\right)-$ which represent positive and negative correlations between samples and attributes, respectively. Attributes represented with symbols $(+)$ or $(-)$, were identified as having a significant impact on the overall liking of the salty cookies through Penalty Analysis 
grass-pea based tempeh flour at a $5 \%$ flour substitution level lead to considerable weaker association with all those attributes except for odor of 'water \& salt cookie', while at a $10 \%$ substitution level there was no correlation to odor of 'water \& salt cookie' and a positive association was found to 'wholegrain' appearance and odor.

The attributes identified through penalty analysis as significantly improving overall liking of the samples were 'tempting' appearance and 'salty' taste, which were associated with the control sample and cookie with $5 \%$ flour substitution. Regarding attributes with negative impact on the overall liking, these were related to appearance ('wholegrain' and 'dark color') and were associated with the cookies with higher flour substitution (20 and $30 \%)$.

\section{Discussion}

In this study, children aged between 8 and 12 years old were able to differentiate different samples of salty and sweet cookies incorporating various levels of grass pea-based tempeh flour, not only in terms of overall liking but also through the sensory profile of the samples. This work further illustrates the appropriateness of using CATA questions to evaluate children's perception of sensory profile, and their ability to generate CATA ballots through the application of carefully conducted focus groups.

In this research, the application of a 7-point facial hedonic scale allowed children to discriminate different samples (Table 3), further demonstrating that children are able to correctly use these kind of scales not only to rate their overall liking but also to discriminate different samples (Laureati \& Pagliarini, 2018; Laureati et al., 2015). The application of the CATA methodology was also successful in obtaining further insights into how children perceive different food products. The level of discrimination of the attributes present in the CATA ballot (Table 2) was dependent of the cookie typology - a greater discrimination was observed for sweet cookies (71\%, 15/21 attributes), but the level for salty cookies was also very relevant (43\%, 9/21 attributes). The ballot employed in this study had a total of 21 sensory attributes, a higher number if compared with previous studies using the same approach (Schouteten et al., 2017; Verwaeren et al., 2019). Nonetheless, the number of discriminating attributes under blind evaluation was very similar to those studies and children were able to perform the CATA methodology and to elaborate different sensory profiles.

Concerning the development of the CATA ballot, most attributes elicited by children were related to the appearance and for both salty and sweet cookies all the attributes related to appearance discriminated the samples (Table 2). In previous studies, it has been reported that most of the attributes that children elicit for food products are related to appearance and that the evaluation of these attributes is more analytical when compared to other sensory dimensions (Rose et al., 2004; Sune et al., 2002). Furthermore, it has been reported that children use vision more than adults when making their food decisions (Dovey et al., 2012). A similar evaluation was also observed for both salty and sweet cookies, since an increase in the amount of fermented grass-pea flour lead to an increase in 'dark color' and 'wholegrain' appearance and decrease in 'tempting' appearance. Moreover, the attributes related to appearance had a significant impact on the overall liking of the samples for both typologies. Previous studies performed with speculoos (a traditional cookie from Belgium and Netherlands), have also noted that products associated with a 'dark brown color' had lower overall liking scores (Schouteten et al., 2017). The importance of appearance in children's acceptance of food products can also be explained by the "visual exposure" theory, in which the simple exposure to a certain food product leads to a greater acceptance and consumption of the food product (Rioux, Lafraire, \& Picard, 2018). This strategy is particularly helpful in neophobic or picky eaters, which are more prone to reject foods on mere sight (Dovey, Staples, Gibson, \& Halford, 2008). Color seems to be one of the major attributes that controls food rejection in children. This happens because food categorization has been shown to be mainly color- dependent, as it provides information regarding the typicality of a certain product, unlike shape or texture (Rioux, Picard, \& Lafraire, 2016). In fact, in this study the researchers found that dark color is also strongly related to disliking.

Regarding the attributes related to texture, only one attribute ('crunchy') discriminated sweet cookies while for salty cookies no attribute related to texture discriminated the samples. In the sweet cookies, the samples with highest overall liking scores were the ones associated with this attribute ('crunchy') and it had a significant impact on samples' overall liking, according to the penalty analysis. These results are in accordance with studies that have been performed with speculoos, in which the samples with the highest overall liking were associated with a crunchy texture and it had a significant impact on the overall liking (Schouteten et al., 2017; Verwaeren et al., 2019). Nonetheless, it has also been reported that children dislike crunchy or chewy textures, preferring foods with low complexity (Popper \& Kroll, 2011) and that more neophobic children have a higher preference for softer textures (Laureati et al., 2020). However, the preference for crunchy textures depends on the type of food that is being consumed. In the case of pastry products, this attribute may be related to the freshness of the product (Heenan, Hamid, Dufour, Harvey, \& Delahunty, 2009).

For the taste dimension, striking differences were observed for each type of cookies, given that a higher number of discriminating attributes was observed for sweet cookies than for salty cookies. This could be explained by the fact that children are more familiar with sweet-type cookies, leading to a higher discrimination for taste attributes. These differences in taste attributes discrimination could explain the higher differences that were registered for overall liking in the sweet cookies (e. g. only for sweet cookies the samples were associated with clear negative attributes such as 'unpleasant' taste and 'unpleasant aftertaste'). For sweet cookies, it was evident that the samples with the highest overall liking were associated with familiar tastes (such as 'Maria cookie' and 'Water \& salt cookie', which are two of the most consumed types of cookies in Portugal, (Lopes et al., 2017)) and sweet taste. The preference and acceptance of sweet products by children is well-documented. Positive responses to sweet taste are generally inborn, and the preference for sweet taste is universal for children among the world, and only declines during mid-adolescence (Mennella, 2014). In the case of salty cookies, the only differences were found for 'salty' and 'toasted' taste, with samples with highest overall liking being linked with 'salty' taste and samples with the lowest overall liking being associated with a 'toasted' taste. Saltiness preference in children is more complex that sweet preference, but positive responses to saltiness is also inborn and there are several reports in which the overall liking of food products (including crackers) by children is increased by the addition of salt (Liem, 2017; Mennella, 2014).

The individual characteristics of the children, particularly the level of neophobia, seemed to greatly impact how children perceived the different samples (Table 3). Neophobia has been associated with reduced preferences for almost all food groups, with this effect being more prominent in healthy foods such as fruits or vegetables (Howard et al., 2012; Russell \& Worsley, 2008). Therefore, it can be responsible for a less diversified diet (Gomes et al., 2018), along with a possible lack of essential nutrients (Carruth et al., 1998). In this study, it was possible to observe that the CFNS level of children was negatively associated with the samples overall liking, with the most neophobic group giving lower overall liking scores for both salty and sweet cookies, regardless of the level of inclusion of fermented grass-pea flour (even for the control samples, neophobic children gave lower scores). One possible explanation for this behavior is that neophobic/picky children have lower food discriminability capacity, given that these children do not accept new food products and thus have fewer learning opportunities with sensory attributes (Rioux et al., 2016). The results of this study are very similar to the ones reported in literature (Laureati, Bergamaschi, \& Pagliarini, 2015; Laureati, Bertoli, et al., 2015; Laureati, Cattaneo, Bergamaschi, Proserpio, \& Pagliarini, 2016; Proserpio et al., 2020, 2019) in which 
more neophobic children gave lower overall liking scores than children who were less neophobic. However, in the work by Proserpio et al. (2019) this effect of food neophobia was more pronounced in increasingly modified samples. Additionally, it should be noted that these studies used a Food Neophobia questionnaire designed to be selfreported by children (Laureati, Bergamaschi, et al., 2015) which is different from the applied Food Neophobia questionnaire in this work (Pliner, 1994), in which parents answer the questionnaire. The use of the questionnaire developed by Pliner (1994) can have some limitations because it can underestimate the role of the child in the process (Aldridge, Dovey, \& Halford, 2009) and parents may project their own behaviors onto those of their children (Mata, Scheibehenne, \& Todd, 2008) and can only report about their children's behavior when they are under their control/view (Proserpio et al., 2020).

\section{Conclusion}

Children aged 8-12 years old were able to elaborate a CATA ballot for the evaluation of innovative food products (salty and sweet cookies incorporating fermented grass-pea flour) and to correctly employ this methodology to elaborate different sensory profiles. Attributes related to appearance, crunchy texture and sweet/salty taste were the attributes that significantly impacted children's acceptance of food products, which is in accordance with studies present in literature. Furthermore, it was also possible to observe that the level of neophobia is negatively associated with the children's sensory perception of food products, given that neophobic children consistently gave lower overall liking scores for all the tested samples.

\section{Declaration of Competing Interest}

The authors declare that they have no known competing financial interests or personal relationships that could have appeared to influence the work reported in this paper.

\section{Acknowledgments}

This research project received funding from the Fundação para a Ciência e a Tecnologia (FCT) through the research project QuaLaty, under the grant agreement no. PTDC/AGR-TEC/0992/2014. Author MCVP was also supported by FCT, through Investigator 2015 contract IF/01337/2014. Author C. Rocha acknowledges Industry Doctoral Grant No. SFRH/BDE/100483/2014, and author J. Ribeiro acknowledges Doctoral Grant No. SFRH/BD/147409/2019 funded by FCT. This work was supported by national funds from the FCT through the research units LEAF (UID/AGR/04129/2013), GREEN-IT (UID/Multi/04551/ 2019) and GreenUPorto (UIDB/05748/2020 and UIDP/05748/2020).

\section{References}

Aldridge, V., Dovey, T. M., \& Halford, J. C. G. (2009). The role of familiarity in dietary development. Developmental Review, 29, 32-44. https://doi.org/10.1016/j. dr.2008.11.001

Ares, G., Barreiro, C., Deliza, R., Giménez, A., \& Gámbaro, A. (2010). Application of a check-all-that-apply question to the development of chocolate milk desserts. Journal of Sensory Studies, 25(SUPPL. 1), 67-86. https://doi.org/10.1111/j.1745459X. 2010.00290.x

Ares, G., Dauber, C., Fernández, E., Giménez, A., \& Varela, P. (2014). Penalty analysis based on CATA questions to identify drivers of liking and directions for product reformulation. Food Quality and Preference, 32, 65-76. https://doi.org/10.1016/j. foodqual.2013.05.014

Ares, G., \& Jaeger, S. R. (2013). Check-all-that-apply questions: Influence of attribute order on sensory product characterization. Food Quality and Preference, 28(1), 141-153. https://doi.org/10.1016/j.foodqual.2012.08.016

Ares, G., Jaeger, S. R., Bava, C. M., Chheang, S. L., Jin, D., Gimenez, A., Vidal, L., Fiszman, S. M., \& Varela, P. (2013). CATA questions for sensory product characterization: Raising awareness of biases. Food Quality and Preference, 30, 114-127. https://doi.org/10.1016/j.foodqual.2013.04.012

Ares, G., Varela, P., Rado, G., \& Giménez, A. (2011). Are consumer profiling techniques equivalent for some product categories? The case of orange-flavoured powdered drinks. International Journal of Food Science \& Technology, 46(8), 1600-1608. https:// doi.org/10.1111/j.1365-2621.2011.02657.x

Bardin, L. (1977). L'analyse de contenu. Presses Universitaires de France.

Batista, A. P., Niccolai, A., Bursic, I., Sousa, I., Raymundo, A., Rodolfi, L.,

Tredici, M. R. (2019). Microalgae as functional ingredients in savory food products: Application to wheat crackers. Foods, 8(12). https://doi.org/10.3390/foods8120611

Birch, L., Savage, J. S., \& Ventura, A. (2007). Influences on the Development of Children's Eating Behaviours: From Infancy to Adolescence. Canadian journal of dietetic practice and research: A publication of Dietitians of Canada = Revue canadienne de la pratique et de la recherche en dietetique : Une publication des Dietetistes du Canada, 68(1), s1-s56.

Birch, L. L. (1999). Development of food preferences. Annual Review of Nutrition, 19, 41-62. https://doi.org/10.1146/annurev.nutr.19.1.41

Caporale, G., Policastro, S., Tuorila, H., \& Monteleone, E. (2009). Hedonic ratings and consumption of school lunch among preschool children. Food Quality and Preference, 20(7), 482-489. https://doi.org/10.1016/j.foodqual.2009.04.008

Cardinal, P., Zamora, M. C., Chambers, E., IV, Carbonell Barrachina, Á., \& Hough, G. (2015). Convenience sampling for acceptability and CATA measurements may provide inaccurate results: A case study with fruit-flavored powdered beverages tested in Argentina, Spain and U.S.A. Journal of Sensory Studies, 30(4), 295-304. https://doi.org/10.1111/joss.12158

Carruth, B. R., Skinner, J., Houck, K., Moran, J., 3rd, Coletta, F., \& Ott, D. (1998). The phenomenon of "picky eater": A behavioral marker in eating patterns of toddlers. Journal of the American College of Nutrition, 17(2), 180-186. https://doi.org/ 10.1080/07315724.1998.10718744

Coulthard, H., \& Blissett, J. (2009). Fruit and vegetable consumption in children and their mothers. Moderating effects of child sensory sensitivity. Appetite, 52(2), 410-415. https://doi.org/10.1016/j.appet.2008.11.015

De Pelsmaeker, S., Schouteten, J., \& Gellynck, X. (2013). The consumption of flavored milk among a children population. The influence of beliefs and the association of brands with emotions. Appetite, 71, 279-286. https://doi.org/10.1016/j. appet.2013.08.016

Dooley, L., Lee, Y. S., \& Meullenet, J. F. (2010). The application of check-all-that-apply (CATA) consumer profiling to preference mapping of vanilla ice cream and its comparison to classical external preference mapping. Food Quality and Preference, 21 (4), 394-401. https://doi.org/10.1016/i.foodqual.2009.10.002

Dovey, T. M., Aldridge, V. K., Dignan, W., Staples, P. A., Gibson, E. L., \& Halford, J. C. G. (2012). Developmental differences in sensory decision making involved in deciding to try a novel fruit. British Journal of Health Psychology, 17(2), 258-272. https://doi. org/10.1111/j.2044-8287.2011.02036.x

Dovey, T. M., Staples, P. A., Gibson, E. L., \& Halford, J. C. (2008). Food neophobia and 'picky/fussy' eating in children: A review. Appetite, 50(2-3), 181-193. https://doi. org /10.1016/j.appet.2007.09.009

Fradinho, P., Nunes, M. C., \& Raymundo, A. (2015). Developing consumer acceptable biscuits enriched with Psyllium fibre. Journal of Food Science and Technology, 52(8), 4830-4840. https://doi.org/10.1007/s13197-014-1549-6

Gallo, K. E., Swaney-Stueve, M., \& Chambers, D. H. (2017). A focus group approach to understanding food-related emotions with children using words and emojis. Journal of Sensory Studies, 32(3), Article e12264. https://doi.org/10.1111/joss.12264

Gomes, A. I., Barros, L., Pereira, A. I., Roberto, M. S., \& Mendonça, M. (2018). Assessing children's willingness to try new foods: Validation of a Portuguese version of the child's food neophobia scale for parents of young children. Food Quality and Preference, 63, 151-158. https://doi.org/10.1016/j.foodqual.2017.09.002

Heenan, S. P., Hamid, N., Dufour, J.-P., Harvey, W., \& Delahunty, C. M. (2009). Consumer freshness perceptions of breads, biscuits and cakes. Food Quality and Preference, 20(5), 380-390. https://doi.org/10.1016/j.foodqual.2009.02.008

Howard, A. J., Mallan, K. M., Byrne, R., Magarey, A., \& Daniels, L. A. (2012). Toddlers' food preferences. The impact of novel food exposure, maternal preferences and food neophobia. Appetite, 59(3), 818-825. https://doi.org/10.1016/j.appet.2012.08.022

Kelly, B., Halford, J. C. G., Boyland, E. J., Chapman, K., Bautista-Castaño, I., Berg, C., .. Summerbell, C. (2010). Television food advertising to children: A global perspective. American Journal of Public Health, 100(9), 1730-1736. https://doi.org/10.2105/ AJPH.2009.179267

King, S. C., Meiselman, H. L., \& Carr, B. T. (2013). Measuring emotions associated with foods: Important elements of questionnaire and test design. Food Quality and Preference, 28(1), 8-16. https://doi.org/10.1016/j.foodqual.2012.08.007

Koivisto, U.-K., \& Sjödén, P.-O. (1996). Food and general neophobia in Swedish families: Parent-child comparisons and relationships with serving specific foods. Appetite, 26 (2), 107-118. https://doi.org/10.1006/appe.1996.0009

Laureati, M., Bergamaschi, V., \& Pagliarini, E. (2015). Assessing childhood food neophobia: Validation of a scale in Italian primary school children. Food Quality and Preference, 40, 8-15. https://doi.org/10.1016/j foodqual.2014.08.003

Laureati, M., Bertoli, S., Bergamaschi, V., Leone, A., Lewandowski, L., Giussani, B., Pagliarini, E. (2015). Food neophobia and liking for fruits and vegetables are not related to Italian children's overweight. Food Quality and Preference, 40, 125-131. https://doi.org/10.1016/j.foodqual.2014.09.008

Laureati, M., Cattaneo, C., Bergamaschi, V., Proserpio, C., \& Pagliarini, E. (2016). School children preferences for fish formulations: The impact of child and parental food neophobia. Journal of Sensory Studies, 31(5), 408-415. https://doi.org/10.1111/ joss. 12224

Laureati, M., Cattaneo, C., Lavelli, V., Bergamaschi, V., Riso, P., \& Pagliarini, E. (2017). Application of the check-all-that-apply method (CATA) to get insights on children's drivers of liking of fiber-enriched apple purees. Journal of Sensory Studies, 32(2), Article e12253. https://doi.org/10.1111/joss.12253 
Laureati, M., \& Pagliarini, E. (2018). Chapter 13 - new developments in sensory and consumer research with children. In G. Ares, \& P. Varela (Eds.), Methods in consumer research (Vol. 2, pp. 321-353). Woodhead Publishing.

Laureati, M., Pagliarini, E., Toschi, T. G., \& Monteleone, E. (2015). Research challenges and methods to study food preferences in school-aged children: A review of the last 15years. Food Quality and Preference, 46, 92-102. https://doi.org/10.1016/j. foodqual.2015.07.010

Laureati, M., Sandvik, P., Almli, L. V., Sandell, M., Zeinstra, G. G., Methven, L., ... Proserpio, C. (2020). Individual differences in texture preferences among European children: Development and validation of the Child Food Texture Preference Questionnaire (CFTPQ). Food Quality and Preference, 80. https://doi.org/10.1016/j. foodqual.2019.103828

Lehrner, J. P., Glück, J., \& Laska, M. (1999). Odor identification, consistency of label use, olfactory threshold and their relationships to odor memory over the human lifespan. Chemical Senses, 24(3), 337-346. https://doi.org/10.1093/chemse/24.3.337

Liem, D. G. (2017). Infants' and children's salt taste perception and liking: A review. Nutrients, 9(9). https://doi.org/10.3390/nu9091011

Lima, M., Ares, G., \& Deliza, R. (2018). Children and adults' sensory and hedonic perception of added sugar reduction in grape nectar. Journal of Sensory Studies, 33 (2), Article e12317. https://doi.org/10.1111/joss.12317

Lima, M., Ares, G., \& Deliza, R. (2019). Comparison of two sugar reduction strategies with children: Case study with grape nectars. Food Quality and Preference, 71, 163-167. https://doi.org/10.1016/j.foodqual.2018.07.002

Lobstein, T., Baur, L., \& Uauy, R. (2004). Obesity in children and young people: A crisis in public health. Obesity Reviews, 5(Suppl 1), 4-104. https://doi.org/10.1111/ j.1467-789X.2004.00133.x

Lopes, C., Torres, D., Oliveira, A., Severo, M., Alarcão, V., Guiomar, S., Mota, J., Ramos, E. (2017). Inquérito Alimentar Nacional e de Atividade Física, IAN-AF 20152016: Relatório de resultados. Universidade do Porto. ISBN: 978-989-746-181-1 Available in: www.ian-af.up.pt. [in Portuguese].

Macfie, H. J., Bratchell, N., Greenhoff, K., \& Vallis, L. V. (1989). Designs to balace the effect of order of presentation and first-order carry-over effects in hall tests. Journal of Sensory Studies, 4(2), 129-148. https://doi.org/10.1111/j.1745-459X.1989. tb00463.x

Mata, J., Scheibehenne, B., \& Todd, P. M. (2008). Predicting children's meal preferences: How much do parents know? Appetite, 50, 367-375. https://doi.org/10.1016/j. appet.2007.09.001

Mennella, J. A. (2014). Ontogeny of taste preferences: Basic biology and implications for health. American Journal of Clinical Nutrition, 99(3), 704s-711s. https://doi.org/ 10.3945/ajen.113.067694

Meyners, M., \& Castura, J. C. (2014). Check-all-that apply questions. In P. Varela, \& G. Ares (Eds.), Novel techniques in sensory characterization and consumer profiling. Boca Raton, FL: CRC Press.

Meyners, M., Castura, J. C., \& Carr, B. T. (2013). Existing and new approaches for the analysis of CATA data. Food Quality and Preference, 30(2), 309-319. https://doi.org/ 10.1016/j.foodqual.2013.06.010

Mitterer Daltoé, M. L., Breda, L. S., Belusso, A. C., Nogueira, B. A., Rodrigues, D. P., Fiszman, S., \& Varela, P. (2017). Projective mapping with food stickers: A good tool for better understanding perception of fish in children of different ages. Food Quality and Preference, 57, 87-96. https://doi.org/10.1016/j.foodqual.2016.12.003

Olsen, A., van Belle, C., Meyermann, K., \& Keller, K. L. (2011). Manipulating fat content of familiar foods at test-meals does not affect intake and liking of these foods among children. Appetite, 57(3), 573-577. https://doi.org/10.1016/j.appet.2011.07.007

Parente, M. E., Manzoni, A. V., \& Ares, G. (2011). External preference mapping of commercial antiaging creams based on consumer's creams based on consumer's response to a Check-All-That-Apply question. Journal of Sensory Studies, 26(2), 158-166. https://doi.org/10.1111/j.1745-459X.2011.00332.x

Partridge, H. L., Edwards, S. L., \& Thorpe, C. E. (2010). Evidence-based practice : Information professionals' experience of information literacy in the workplace. In A. Lloyd, \& S. Talja (Eds.), Practising information literacy: Bringing theories of learning, practice and information literacy together (pp. 273-298). Wagga Wagga, N.S.W.: Centre for Information Studies, Charles Sturt University.

Pliner, P. (1994). Development of measures of food neophobia in children. Appetite, 23 (2), 147-163. https://doi.org/10.1006/appe.1994.1043
Popper, R., \& Kroll, J. J. (2011). Consumer testing of food products using children. In D. Kilcast, \& F. Angus (Eds.), Developing Children's Food Products, 9 pp. 163-187). Woodhead Publishing.

Proserpio, C., Almli, V. L., Sandvik, P., Sandell, M., Methven, L., Wallner, M., .. Laureati, M. (2020). Cross-national differences in child food neophobia: A comparison of five European countries. Food Quality and Preference, 81. https://doi. org/10.1016/j.foodqual.2019.103861

Proserpio, C., Lavelli, V., Gallotti, F., Laureati, M., \& Pagliarini, E. (2019). Effect of vitamin D2 fortification using Pleurotus ostreatus in a whole-grain cereal product on child acceptability. Nutrients, 11. https://doi.org/10.3390/nu11102441

Ribeiro, J. C., Lima, R. C., Maia, M. R. G., Almeida, A. A., Fonseca, A. J. M., Cabrita, A. R. J., \& Cunha, L. M. (2019). Impact of defatting freeze-dried edible crickets (Acheta domesticus and Gryllodes sigillatus) on the nutritive value, overall liking and sensory profile of cereal bars. LWT-Food Science and Technology, 113. https://doi.org/10.1016/j.lwt.2019.108335

Rioux, C., Lafraire, J., \& Picard, D. (2018). Visual exposure and categorization performance positively influence 3- to 6-year-old children's willingness to taste unfamiliar vegetables. Appetite, 120, 32-42. https://doi.org/10.1016/j. appet.2017.08.016

Rioux, C., Picard, D., \& Lafraire, J. (2016). Food rejection and the development of food categorization in young children. Cognitive Development, 40, 163-177. https://doi. org/10.1016/j.cogdev.2016.09.003

Rose, G., Laing, D. G., Oram, N., \& Hutchinson, I. (2004). Sensory profiling by children aged 6-7 and 10-11 years. Part 1: A descriptor approach. Food Quality and Preference, 15(6), 585-596. https://doi.org/10.1016/j.foodqual.2003.11.008

Russell, C. G., \& Worsley, A. (2008). A Population-based Study of Preschoolers' Food Neophobia and Its Associations with Food Preferences. Journal of Nutrition Education and Behavior, 40(1), 11-19. https://doi.org/10.1016/j.jneb.2007.03.007

Schouteten, J. J., De Steur, H., Lagast, S., De Pelsmaeker, S., \& Gellynck, X. (2017). Emotional and sensory profiling by children and teenagers: A case study of the check-all-that-apply method on biscuits. Journal of Sensory Studies, 32(1), Article e12249. https://doi.org/10.1111/joss.12249

Schouteten, J. J., Verwaeren, J., Gellynck, X., \& Almli, V. L. (2019). Comparing a standardized to a product-specific emoji list for evaluating food products by children. Food Quality and Preference, 72, 86-97. https://doi.org/10.1016/j. foodqual.2018.09.007

Schouteten, J. J., Verwaeren, J., Lagast, S., Gellynck, X., \& De Steur, H. (2018). Emoji as a tool for measuring children's emotions when tasting food. Food Quality and Preference, 68, 322-331. https://doi.org/10.1016/j.foodqual.2018.03.005

Sune, F., Lacroix, P., \& Huon de Kermadec, F. (2002). A comparison of sensory attribute use by children and experts to evaluate chocolate. Food Quality and Preference, 13(7), 545-553. https://doi.org/10.1016/S0950-3293(02)00057-5

Tibbott, S. (2004). Tempeh: The "Other"' white beancake. In Y. H. Hui, L. M. Goddik, A. S. Hansen, J. Josephsen, W. K. Nip, P. S. Stanfield, \& F. Toldra (Eds.), Handbook of food and beverage fermentation technology (pp. 533-570). New York: Marcel Dekker.

Varela, P., \& Salvador, A. (2014). Structured sorting using pictures as a way to study nutritional and hedonic perception in children. Food Quality and Preference, 37, 27-34. https://doi.org/10.1016/j.foodqual.2014.04.009

Vaz Patto, M. C. (2006). Lathyrus improvement for resistance against biotic and abiotic stresses: From classical breeding to marker assisted selection. Euphytica, 147(1-2). https://doi.org/10.1007/s10681-006-3607-2. pp. 133-147-2006.

Vaz Patto, M. C., \& Araújo, S. S. (2016). Positioning Portugal into the context of world production and research in grain legumes. Revista de Ciências Agrárias, 39(4), 471-489. https://doi.org/10.19084/RCA16161

Verwaeren, J., Gellynck, X., Lagast, S., \& Schouteten, J. J. (2019). Predicting children's food choice using check-all-that-apply questions. Journal of Sensory Studies, 34(1), Article e12471. https://doi.org/10.1111/joss.12471

WHO. (2012). Population-based approaches to childhood obesity prevention. Geneva, Switzerland: World Health Organization Press.

Zeinstra, G. G., Koelen, M. A., Kok, F. J., \& de Graaf, C. (2010). The influence of preparation method on children's liking for vegetables. Food Quality and Preference, 21(8), 906-914. https://doi.org/10.1016/j.foodqual.2009.12.006 